\title{
A Method by Which to Assess the Scalability of Field-Based Fitness Tests of Cardiorespiratory Fitness Among Schoolchildren
}

\author{
Sarah Domone ${ }^{1} \cdot$ Steven Mann $^{1} \cdot$ Gavin Sandercock $^{1,2} \cdot$ Matthew Wade $^{1} \cdot$ \\ Chris Beedie ${ }^{1,3}$
}

Published online: 26 May 2016

(c) The Author(s) 2016. This article is published with open access at Springerlink.com

\begin{abstract}
Previous research has reported the validity and reliability of a range of field-based tests of children's cardiorespiratory fitness. These two criteria are critical in ensuring the integrity and credibility of data derived through such tests. However, the criterion of scalability has received little attention. Scalability determines the degree to which tests developed on small samples in controlled settings might demonstrate real-world value, and is of increasing interest to policymakers and practitioners. The present paper proposes a method by which the scalability of cardiorespiratory field-based tests suitable for schoolaged children might be assessed. We developed an algorithm to estimate scalability based on a six-component model; delivery, evidence of operating at scale, effectiveness, costs, resource requirements and practical implementation. We tested the algorithm on data derived through a systematic review of research that has used relevant fitness tests. A total of 229 studies that had used field based cardiorespiratory fitness tests to measure children's fitness were identified. Initial analyses indicated that the 5-min run test did not meet accepted criteria for reliability, whilst the 6-min walk test likewise failed to meet the criteria for validity. Of the remainder, a total of 28 studies met the inclusion criteria, 22 reporting the 20-m shuttle-run and seven the 1-mile walk/run. Using the scalability algorithm
\end{abstract}

Sarah Domone

sarahdomone@ukactive.org.uk

1 ukactive Research Institute, 26-28 Bedford Row, London WC1R 4HE, UK

2 Centre for Sport and Exercise Science, School of Biological Sciences, University of Essex, Colchester, UK

3 School of Human and Life Sciences, Canterbury Christ Church University, Canterbury, Kent, UK we demonstrate that the 20 -m shuttle run test is substantially more scalable than the 1-mile walk/run test, with tests scoring 34/48 and 25/48, respectively. A comprehensive analysis of scalability was prohibited by the widespread non-reporting of data, for example, those relating to costeffectiveness. Of all sufficiently valid and reliable candidate tests identified, using our algorithm the 20-m shuttle run test was identified as the most scalable. We hope that the algorithm will prove useful in the examination of scalability in either new data relating to existing tests or in data pertaining to new tests.

\section{Key Points}

Previous research has reported the validity and reliability of a number of tests of children's fitness.

Our systematic review indicated that the 5-min run test did not meet accepted criteria for reliability, whilst the 6-min walk test failed to meet the criteria for validity.

We further identified that of all sufficiently valid and reliable tests of children's fitness, the 20-m shuttle run test was identified as the most scalable.

\section{Introduction}

The health and fitness of children is increasingly recognised as a core component of public health. Two reasons for this growing emphasis are evident. Firstly, poor health 
adversely affects the quality of life, and the physical, academic and social development of children. Second, poor health in childhood may predispose to certain diseases and is often therefore predictive of poor health in adulthood [1]. To this end, the UK Chief Medical Officer [2] stated "the introduction of a standardised school-based fitness assessment in England may have multiple benefits that extend beyond the benefits for the individual". Such assessment could focus on the measurement of physical activity, and/or the measurement of the results of physical activity. Methods might range from the very basic such as the total time children spend in physical education (PE) lessons and/or the number of children who take part in extracurricular physical activity, to the more complex, such as the evaluation of motor skills and physical literacy, and/or the measurement of cardio-respiratory fitness.

However, none of the above measures are currently mandated in UK schools. The current mandated measure, the National Child Weight Measurement Programme (NCMP, http://www.hscic.gov.uk/ncmp), measures body mass index (BMI). The NCMP represents one of, if not the only, proxy measures of a child's health across the UK. Given its broad coverage, it provides valuable data on child health at a local and national population level. Arguably, however, the BMI of a child is a crude metric at best, often saying as much about genetics and somatotype as about physical activity levels and health. In fact BMI in young childhood is at best only moderately predictive of subsequent adult health status [3].

Public health agencies in the UK are encouraging novel interventions to increase levels of childhood physical activity. However, the widespread lack of routine data collection identified above renders it problematic to evaluate the true impact of any such interventions. It also renders it almost impossible to set benchmarks, to identify local pockets of excellence (or indeed underperformance), or to calculate the cost-effectiveness of interventions. Whilst many areas of public health policy are characterised by a clear evidence-based strategy, decisions relating to the health and fitness of the nation's children are often made in an evidence vacuum.

In the short- to medium-term what is required is a means of testing the health and fitness of children that is not only valid and reliable, but is also ethical and cost-effective. It is also abundantly clear that any large-scale fitness testing of children would need to be conducted in the field as opposed to the laboratory, as the provision of resources required for the latter would be prohibitive in the extreme.

The decision as to which test should be used is challenging. Data pertaining to the reliability and validity of tests of children's fitness are widely available. For example, CastroPiñero et al. [4] conducted a systematic review of the criterion related validity of field based fitness testing methods in children. The results of 73 studies suggested strong support for the 20-m shuttle run test as a valid means by which to estimate cardiorespiratory fitness in children and adolescents. Likewise, Artero et al. [5] conducted a systematic review to determine the reliability of children's fitness testing methods and reported the most reliable field-based test of cardio-respiratory fitness was the 20-m shuttle run test.

However, whilst validity and reliability are of critical importance, in the field-test context it is often required that further criteria are met. Whilst receiving little attention in the scientific literature, the criterion of scalability, that is the potential for the extension into real-world policy and/or practice of interventions or tests shown to be efficacious in controlled settings [6] is often critical to policymakers and practitioners.

\subsection{Aims of the Present Review}

Our aim is to propose a novel framework by which researchers and practitioners might assess the scalability of field-based fitness tests appropriate for primary school children aged $8-11$ years. We propose an algorithm by which the scalability of a candidate test can be evaluated. We then apply this algorithm to data identified via a systematic review to assess the scalability of children's fitness tests.

\section{Methodology}

\subsection{Identification of Components of Scalability}

Scalability is to all intents a latent variable and cannot be directly measured. In order to overcome this, a collection of items or components hypothesised to co-vary with the latent variable were identified used as a proxy measurement [7].

Whilst the concept of scalability is becoming progressively more significant in public health, there is only limited information relating to its definition and core constituents. Terms used to described scalability have been applied in many different ways and contexts, with little consistency or rigour [6]. In an attempt to bring some clarity to terminology used, Milat et al. [6, 8] proposed eight core constituents: (1) delivery, (2) effectiveness, (3) cost-effectiveness, (4) evaluation, (5) reach and adoption, (6) evidence of operating at scale, (7) resource requirement and (8) practical implementation issues.

We adapted the eight criteria proposed by Milat et al. [6] to six components for the specific case of field-based fitness testing methods. Some components were represented by a single variable, whilst other components were constructed using multiple variables. These components and related variables are presented in Table 1. 


$$
\text { [intum }
$$




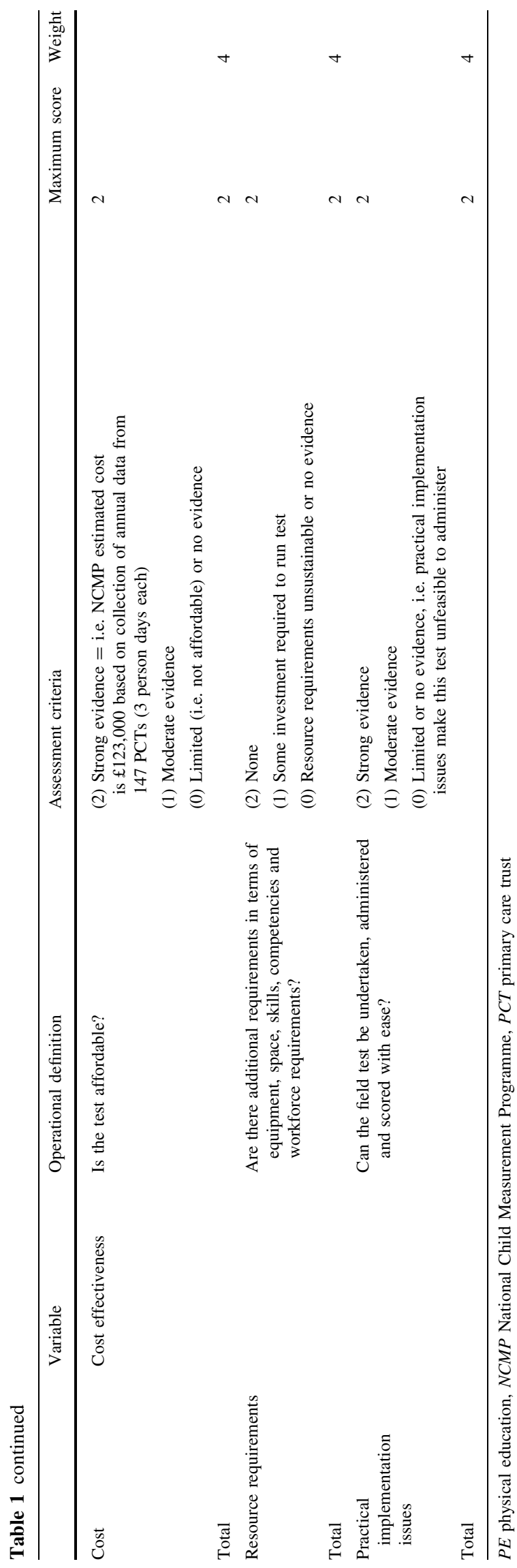

\subsection{Algorithm Construction and Scoring}

We constructed an algorithm as the sum of weighted scores for each of the core constituents of the scalability framework:

$\left\{x_{1}, x_{2}, x_{3}, \ldots, x_{n}\right\}$

In this algorithm each $x_{n}$ represented one core constituent $\mathrm{n}$ of the scalability framework, i.e. delivery. Constituents of the algorithm were weighted as described below:

$X_{\text {score }}=\sum_{i=1}^{n} w_{i} x_{i}$

Each single variable of a component could take a value from 0 to 2, and these variable scores were summed to produce each component score. A maximum of 8 points was possible for each of the six components (Table 1), resulting in a possible maximum scalability score of 48 for each test. We had no a priori reason to justify weighting certain components more heavily than others, so by increasing the weighting of components with low numbers of variables we were able to ensure that each component contributed equally to the overall score (however, excluding tests that did not meet validity and reliability criteria in effect weighted these two variables highly in the scalability analysis).

\subsection{Systematic Review}

To facilitate the testing of the scalability algorithm, a systematic review of studies reporting tests of children's fitness was conducted. The objective of this review was to ensure that we only established the scalability of tests that demonstrate sufficient validity and reliability.

\subsubsection{Inclusion Criteria}

To be included in the review, papers had to report a study of one or more of the fitness tests addressed in two recent systematic reviews [4,5], namely the 20-m shuttle run, 1-mile run, 6-min walk, and 5-min run. Fitness tests meeting these criteria were assessed against three criteria likely critical to the successful implementation of fitness testing of schoolchildren; the validity of the test for use with children aged 8-18 years old, the reliability of the test in this age group, and the applicability of the test, that is whether a test could be implemented in a school setting as part of usual PE lessons, albeit by specially trained staff. These primary criteria were considered fundamental to the child fitness measurement scenario described in the introduction. 


\subsubsection{Evidence Criteria}

A three-tier classification of evidence quality was used [4], albeit in this case referring to the validity and reliability of the tests: (1) strong evidence, that is consistent findings in three or more studies; (2) moderate evidence, that is consistent findings in two studies; and (3) inconsistent results found in multiple studies, results based on one single study, or results indicate low scalability or no information found (Fig. 1).

\subsubsection{Literature Search}

The literature search was undertaken between May and July 2015 using the PubMed database. Key words
Fig. 1 Flowchart of test assessment. $P E$ physical education

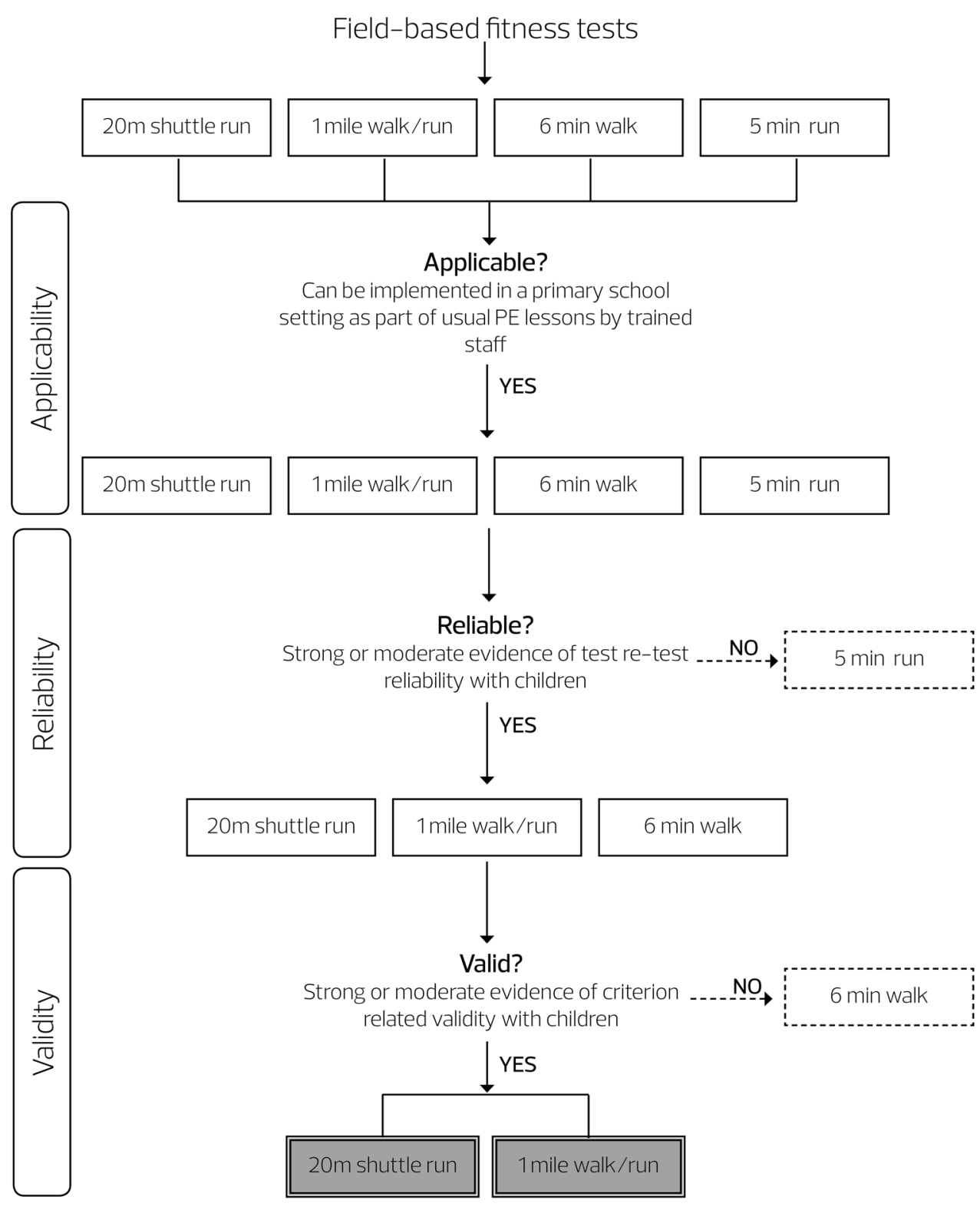

Levels of evidence for criterion-related validity of the field-based fitness tests were defined as follows: Strong evidence: consistent findings in three or more studies; Moderate evidence: consistent findings in two studies:

Limited evidence: inconsistent results found in multiple studies, results based on one single study, or results indicate low scalability or no information found. 
Table 2 Details of review items relating to scalability framework

\begin{tabular}{|c|c|c|c|}
\hline Component & Variable & Operational definition & Assessment criteria \\
\hline \multirow[t]{4}{*}{ Delivery } & Test environment & $\begin{array}{l}\text { Information relating to whether the field } \\
\text { testing was conducted in a school } \\
\text { setting }\end{array}$ & $\begin{array}{l}\text { Yes }=\text { test performed in a school setting } \\
\text { No }=\text { test not performed in a school setting } \\
\text { NR }\end{array}$ \\
\hline & Test duration & $\begin{array}{l}\text { Expected or actual duration of the field } \\
\text { test protocol reported }\end{array}$ & $\begin{array}{l}\text { Yes }=\text { duration of test/trial reported } \\
\mathrm{NR}\end{array}$ \\
\hline & Testing interval & $\begin{array}{l}\text { Duration relating to the interval over } \\
\text { which the testing was conducted }\end{array}$ & $\begin{array}{l}\text { Yes }=\text { duration reported } \\
\text { NR }\end{array}$ \\
\hline & Delivery staff & $\begin{array}{l}\text { Information relating to the personnel used } \\
\text { to administer the testing protocols and } \\
\text { record the results }\end{array}$ & $\begin{array}{l}\text { Yes }=\text { tests performed by usual service delivery } \\
\text { staff (PE teachers) } \\
\text { No = Researchers or clinicians administered tests } \\
\text { NR }\end{array}$ \\
\hline \multirow[t]{2}{*}{$\begin{array}{l}\text { Evidence of } \\
\text { operating at } \\
\text { scale }\end{array}$} & Sample size & $\begin{array}{l}\text { Evidence that the field test has been used } \\
\text { to assess fitness of young people at a } \\
\text { national/population level }\end{array}$ & $\begin{array}{l}\text { Yes }=\text { field test administered at a national or } \\
\text { international level } \\
\text { Partial = field test has been implemented in } \\
\text { multiple testing settings within a local area } \\
\text { No = small sample used/single school }\end{array}$ \\
\hline & Number of schools & $\begin{array}{l}\text { Evidence that the implementation of the } \\
\text { field test is likely to be acceptable to } \\
\text { multiple target schools when scaled up }\end{array}$ & $\begin{array}{l}\text { Yes }=\text { multiple schools used in study } \\
\text { No }=\text { single or no school used } \\
\text { NR }\end{array}$ \\
\hline \multirow[t]{4}{*}{ Effectiveness } & Validity & $\begin{array}{l}\text { How well a specific test measures what it } \\
\text { intends to measure }\end{array}$ & $\begin{array}{l}\text { Yes }=\text { strong or moderate evidence of } \\
\text { acceptable criterion related validity of test } \\
\text { No }=\text { limited evidence }\end{array}$ \\
\hline & Test-retest reliability & $\begin{array}{l}\text { The consistency of performer/s scoring } \\
\text { over repeated rounds of testing }\end{array}$ & $\begin{array}{l}\text { Yes }=\text { strong or moderate evidence of } \\
\text { acceptable test-retest reliability } \\
\text { No }=\text { limited evidence }\end{array}$ \\
\hline & Reach and adoption & $\begin{array}{l}\text { Differential effect, reach and adoption } \\
\text { across target groups, socioeconomic } \\
\text { status and settings }\end{array}$ & $\begin{array}{l}\text { Yes }=\text { reach and adoption is reported } \\
\text { NR }\end{array}$ \\
\hline & Completion rates & Measure of acceptability to individuals & $\begin{array}{l}\text { Yes }=\text { completion rates are reported } \\
\mathrm{NR}\end{array}$ \\
\hline \multirow[t]{3}{*}{$\begin{array}{l}\text { Cost } \\
\text { considerations }\end{array}$} & Cost effectiveness & $\begin{array}{l}\text { Information relating to the cost of the } \\
\text { field test per head is provided }\end{array}$ & $\begin{array}{l}\text { Yes }=\text { cost per head of test is reported } \\
\text { NR }\end{array}$ \\
\hline & Resource requirements & $\begin{array}{l}\text { Information relating to the required } \\
\text { resources in terms of equipment, space, } \\
\text { skills, competencies, workforce, and } \\
\text { financial requirements provided }\end{array}$ & $\begin{array}{l}\text { Yes }=\text { resource requirements are reported } \\
\text { Partial }=\text { only limited reporting concerning some } \\
\text { elements } \\
\text { NR }\end{array}$ \\
\hline & $\begin{array}{l}\text { Practical implementation } \\
\text { issues/considerations }\end{array}$ & $\begin{array}{l}\text { The ease with which the field test can be } \\
\text { undertaken, administered and scored }\end{array}$ & $\begin{array}{l}\text { Yes }=\text { feasibility/practicality is discussed } \\
\text { Partial = only limited reference to practicality } \\
\text { issues included in discussion } \\
\text { NR }\end{array}$ \\
\hline
\end{tabular}

$P E$ physical education, $N R$ not reported

searched, using multiple combinations of AND/OR phrases, included 'cardiorespiratory fitness', 'children', 'testing', 'field', 'youth', 'adolescents', 'CRF', as well as individual test names. Further papers were identified via examining reference lists of publications already identified.

\subsubsection{Data Extraction}

Operational definitions for scalability characteristics are presented in Table 2. Studies were assessed on whether data relating to these characteristics were reported (Table 3). Information relating to delivery, effectiveness, 


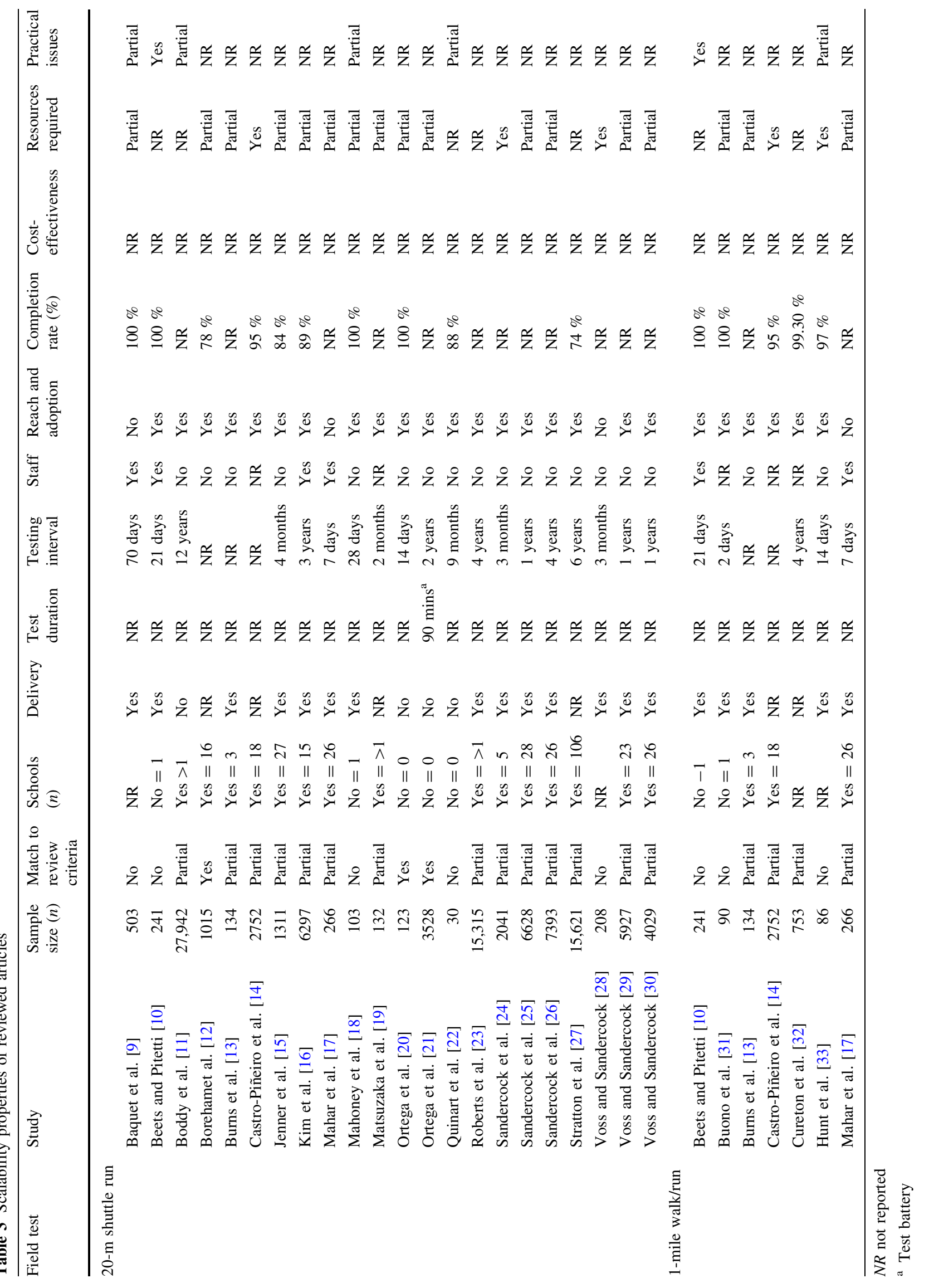


cost-considerations, resource requirement and practical implementation issues were all extracted. A further data extraction form was created to capture information in studies that had directly assessed some aspect of scalability. Items in this form included ease of integration into usual service delivery, burden on delivery staff, preparation requirements, test duration, reach and adoption, completion rates, resource requirements, practical implementation issues and considerations. These are presented in Table 4.

Table 4 Scalability of field based cardiovascular fitness tests

\begin{tabular}{|c|c|c|}
\hline Assessment item & 20-m shuttle run & 1-mile walk/run \\
\hline \multicolumn{3}{|l|}{ Delivery } \\
\hline $\begin{array}{l}\text { Ease of integration } \\
\text { into usual service } \\
\text { delivery }\end{array}$ & $\begin{array}{l}66.7 \% \text { (four teachers) had previous experience of test [34] } \\
\text { Number of children that can be tested at once depends on } \\
\text { space restrictions and capacity for timing } \\
\text { individuals }=1 \mathrm{~m} \text { width per child is recommended } \\
{[35,36]}\end{array}$ & $\begin{array}{l}\text { Number of children that can be tested at once depends on } \\
\text { space restrictions and capacity for timing individuals }\end{array}$ \\
\hline $\begin{array}{l}\text { Burden on delivery } \\
\text { staff and other } \\
\text { stakeholders }\end{array}$ & $\begin{array}{l}\text { Considered feasible based on survey results from six PE } \\
\text { teachers who were asked about factors relating to: (1) } \\
\text { whether children wore appropriate clothing to perform, } \\
\text { (2) ease of instructions, (3) ease of implementation, (4) } \\
\text { rejections and appropriateness of facilities [34] }\end{array}$ & - \\
\hline $\begin{array}{l}\text { Preparation } \\
\text { requirements }\end{array}$ & $\begin{array}{l}\text { Two lines set up } 20 \mathrm{~m} \text { apart, speakers equal distance from } \\
\text { each [36] }\end{array}$ & Measure distance if track unavailable \\
\hline Test duration & $\begin{array}{l}\text { Preparation }=5 \mathrm{~min}, \text { testing }=10 \mathrm{~min} \text { (a group of } 20 \\
\text { individuals) }[34]\end{array}$ & $\begin{array}{l}\text { Mean } \pm \text { SD time for } 8=11 \text { years }=9.2 \pm 1.8 \text { mins } \\
\quad(\text { males }), 10.3 \pm 1.8 \text { mins (females) }[32]\end{array}$ \\
\hline \multicolumn{3}{|l|}{ Effectiveness } \\
\hline Reach and adoption & $\begin{array}{l}\text { Shown to be the preferable choice over the one mile run } \\
\text { for student's motivation for participation [37]. Students } \\
\text { on average reported significantly higher situational } \\
\text { interest in attention demand, exploration intention, and } \\
\text { novelty in the 20-m shuttle run than one mile run [38] }\end{array}$ & $\begin{array}{l}\text { Physical activity engagement (duration of activity, pace, } \\
\text { energy expenditure) was significantly greater in the one } \\
\text { mile run than the } 20 \text {-m shuttle run, particularly for the } \\
\text { low-performing students with a relatively high BMI [38] }\end{array}$ \\
\hline Completion rates & $\begin{array}{l}\text { One participant ( } n=128) \text { stopped due to lower body } \\
\text { muscle cramp, tests were well tolerated, occurrence of } \\
\text { severe DOMS in ten participants }[34]\end{array}$ & - \\
\hline \multicolumn{3}{|l|}{ Resource requirements } \\
\hline Equipment & Audio device, speakers, cones to mark length [36] & Stopwatch \\
\hline Space & $\begin{array}{l}\text { Flat surface, indoor (preferred) or outdoor (weather } \\
\text { dependent), } 20 \mathrm{~m} \text { in length }+ \text { room to turn round, 1-m } \\
\text { width per child [36] }\end{array}$ & $\begin{array}{l}\text { Outside measurable area, flat surface, no standard surface } \\
\text { for this test therefore outdoor } 400 \text {-m athletics track [10], } \\
\text { dirt track [17], or grass athletics track [39] suitable }\end{array}$ \\
\hline Human resource & $\begin{array}{l}\text { Two members of staff }=\text { one to ensure protocols are } \\
\text { followed correctly, one to record scores [36] }\end{array}$ & $\begin{array}{l}\text { Two members of staff }=\text { one to time and one to record } \\
\text { results }[10,17]\end{array}$ \\
\hline Training & $\begin{array}{l}\text { CD provides audio instructions }=\text { no technical training } \\
\text { required [36] }\end{array}$ & No advanced technical training requirements \\
\hline Costs & - & - \\
\hline $\begin{array}{l}\text { Practical } \\
\text { implementation } \\
\text { issues and } \\
\text { considerations }\end{array}$ & $\begin{array}{l}\text { For a single study, } 22(37.9 \%) \text { children and } 25(33.3 \%) \\
\text { adolescents experienced some degree of DOMS, from } \\
\text { whom six children }(10.3 \%) \text { and four adolescents }(5.3 \%) \\
\text { indicated that their DOMS was severe. Three }(2.3 \%) \\
\text { subjects reported having severe pain in the upper body, } \\
29(21.8 \%) \text { in the lower body and } 14(10.5 \%) \text { in the } \\
\text { whole body. Most ( } 39 \text { participants; } 29.3 \%) \text { assumed that } \\
\text { the } 20 \text {-m shuttle run test could be the cause. For } 11 \\
\text { (19\%) children and } 14(18.7 \%) \text { adolescents, DOMS } \\
\text { caused difficulties in daily activities, especially stair } \\
\text { climbing and walking [34] }\end{array}$ & $\begin{array}{l}\text { Participants may have difficulty in developing an } \\
\text { appropriate pace; participants may either start too fast so } \\
\text { that they are not able to keep up the speed all through the } \\
\text { test, or they may start too slow so that when they want to } \\
\text { increase speed, the test is already finished [4] }\end{array}$ \\
\hline
\end{tabular}

$P E$ physical education, DOMS delayed onset muscle soreness, $C D$ compact disc, $S D$ standard deviation, $B M I$ body mass index 
Table 5 Assessment percentage scores for reviewed articles

\begin{tabular}{|c|c|c|c|c|}
\hline \multirow{2}{*}{$\frac{\text { Assessment item }}{\text { Delivery }}$} & \multicolumn{4}{|c|}{ Review items percentage score $(\%)$} \\
\hline & Yes & Partial & No & NR \\
\hline Test context & 72 & & 16 & 12 \\
\hline Test duration & 3 & & & 97 \\
\hline Testing interval & 88 & & & 12 \\
\hline Delivery staff & 20 & & 68 & 12 \\
\hline \multicolumn{5}{|l|}{ Effectiveness } \\
\hline Reach and adoption & 85 & & 15 & \\
\hline Completion rates & 45 & & & 55 \\
\hline \multicolumn{5}{|l|}{ Cost considerations } \\
\hline Cost effectiveness & 0 & & & 100 \\
\hline \multicolumn{5}{|l|}{ Evidence of operating at scale } \\
\hline Sample size & 12 & 56 & 20 & 12 \\
\hline Number of schools & 56 & & 28 & 16 \\
\hline Resource requirements & 11 & 65 & & 24 \\
\hline Practical implementation issues/considerations & 8 & 19 & & 73 \\
\hline
\end{tabular}

$N R$ not reported

\section{Findings}

A total of 229 studies reporting field-based tests of children's cardiorespiratory fitness were identified. Initial analyses indicated that the 5-min run test did not meet the evidence criterion for reliability, whilst the 6-min walk test likewise failed to meet the evidence criterion for validity. A total of 25 studies remained for inclusion in the analysis. Of these, 19 reported the application of the $20-\mathrm{m}$ shuttlerun, and six the one-mile walk/run (note that some studies considered more than one test) (Tables 2 and 3). A further four studies were identified that directly evaluated one or more aspects of scalability of field-based cardiorespiratory fitness tests for children and/or adolescents, and an additional five studies provided information on test protocols. These articles were used to complete the data extraction tables (Tables 3, 4).

Table 5 contains review items score totals for all included articles. For example, the table shows that out of the 25 articles, $8 \%(n=2)$ addressed practical implementation issues. A further $20 \%(n=5)$ received a partial score, with the reduction in rating predominantly due to the lack of information provided regarding practicality issues of administering the test, whilst $72 \%(n=18)$ reported no data relating to this variable.

\subsection{Testing the Algorithm}

The algorithm was used to rate the relative scalability of the 20-m shuttle run test and the 1-mile walk/run. Table 6 presents scores for each of the tests and Fig. 2 shows a spider diagram comparing component scores. The authors independently scored each test and a consensus meeting was arranged to interrogate and resolve any differences. The 20-m shuttle run test scored 34 of a possible 48 whilst the 1-mile walk/run scored 25. This indicates that of the two tests that met the criteria for validity and reliability, the 20 -m shuttle run test is more scalable than the 1-mile walk/ run test. However, a lack of information relating to costeffectiveness/affordability of test delivery, economies of scale and marginal costs was evident and is discussed further below.

\section{Discussion}

Year on year, greater emphasis is being placed on ensuring the real-world impact of scientific research, and the line between science and research on the one hand and policy and practice on the other is not as clearly defined as once it was. Scientists are increasingly expected to conduct research that not only reports traditional scientific metrics, but also data related to the realworld application of those, for example data pertaining to cost-effectiveness in health intervention research. A good example perhaps is that of Robertson et al. [40], who examined not only the validity and reliability of tests of skill in sport, important to those who use the data, but also the feasibility of the tests, equally important to those who conduct the testing.

Whilst the criteria of validity and reliability of children's fitness tests are of major concern to scientists, the 
Table 6 Scalability scores for the 20-m shuttle run test and the 1-mile walk/run test

\begin{tabular}{|c|c|c|c|c|c|}
\hline \multirow[t]{2}{*}{ Component } & \multirow[t]{2}{*}{ Variable } & \multicolumn{2}{|c|}{ 20-m shuttle run test } & \multicolumn{2}{|c|}{$1 \mathrm{mile}$ run/walk } \\
\hline & & Score & Comment & Score & Comment \\
\hline \multirow[t]{4}{*}{ Delivery } & Test context & 2 & 14 studies conducted in school setting & 2 & Five studies conducted in school setting \\
\hline & Test duration & 1 & One study reported $=90$ mins (test battery) & 0 & Not reported \\
\hline & $\begin{array}{l}\text { Testing } \\
\text { interval }\end{array}$ & 2 & $\begin{array}{l}19 \text { studies used test for longitudinal testing, } \\
\text { testing period range } 7 \text { days: } 12 \text { years }\end{array}$ & 2 & $\begin{array}{l}\text { Four studies used test for longitudinal } \\
\text { studies, range } 7 \text { days: } 4 \text { years }\end{array}$ \\
\hline & Delivery staff & 2 & $\begin{array}{l}\text { Three studies reported using PE staff to } \\
\text { administer test }\end{array}$ & 1 & $\begin{array}{l}\text { Two studies reported using PE staff to } \\
\text { administer test }\end{array}$ \\
\hline Total & & 7 & & 5 & \\
\hline \multirow[t]{2}{*}{$\begin{array}{l}\text { Evidence of } \\
\text { operating at } \\
\text { scale }\end{array}$} & Sample size & 2 & $\begin{array}{l}\text { Three studies at population level (national, } \\
\text { international), } 13 \text { studies multiple settings } \\
\text { within local area }\end{array}$ & 2 & $\begin{array}{l}\text { Three studies multiple settings within local } \\
\text { area }\end{array}$ \\
\hline & $\begin{array}{l}\text { Number of } \\
\text { schools }\end{array}$ & 2 & $\begin{array}{l}15 \text { studies administered test in multiple } \\
\text { schools (range 1-106) }\end{array}$ & 1 & $\begin{array}{l}\text { Three studies administered test in multiple } \\
\text { schools (range 1-26) }\end{array}$ \\
\hline Total & & 4 & & 3 & \\
\hline \multirow[t]{4}{*}{ Effectiveness } & Validity & 2 & Strong evidence [4] & 1 & Moderate evidence [4] \\
\hline & $\begin{array}{l}\text { Test-retest } \\
\text { reliability }\end{array}$ & 2 & Strong evidence [5] & 1 & Moderate evidence [5] \\
\hline & $\begin{array}{r}\text { Reach and } \\
\text { adoption }\end{array}$ & 2 & $\begin{array}{l}\text { Reach and adoption across target groups } \\
\text { and differential effect considered in } 19 \\
\text { studies }\end{array}$ & 2 & $\begin{array}{l}\text { Reach and adoption across target groups } \\
\text { and differential effect considered in five } \\
\text { studies }\end{array}$ \\
\hline & $\begin{array}{l}\text { Completion } \\
\text { rates }\end{array}$ & 1 & $\begin{array}{l}\text { Where reported completion rates varied } \\
\text { from } 74-100 \%\end{array}$ & 2 & $\begin{array}{l}\text { Where reported completion rates varied } \\
\text { from } 97-100 \%\end{array}$ \\
\hline Total score & & 7 & & 6 & \\
\hline Cost & $\begin{array}{l}\text { Cost- } \\
\text { effectiveness }\end{array}$ & 0 & Not reported & 0 & Not reported \\
\hline Total & & 0 & & 0 & \\
\hline $\begin{array}{l}\text { Resource } \\
\text { requirements }\end{array}$ & & 1 & $\begin{array}{l}\text { Equipment }=\text { audio device, speakers, cones } \\
\text { to mark length [36]. Space = flat surface, } \\
\text { indoor (preferred) or outdoor (weather } \\
\text { dependent), } 20 \mathrm{~m} \text { in length + room to } \\
\text { turn round, } 1-\mathrm{m} \text { width per child [36]. } \\
\text { Human }=2 \text { members of staff }=\text { one to } \\
\text { ensure protocols are followed correctly, } \\
\text { one to record scores [36]. Training }=\mathrm{CD} \\
\text { provides audio instructions = no } \\
\text { technical training required [36] }\end{array}$ & 1 & $\begin{array}{l}\text { Equipment }=\text { stopwatch. Space }=\text { outside } \\
\text { measurable area, flat surface, no standard } \\
\text { surface for this test therefore outdoor } \\
400 \text {-m athletics track [10], dirt track [17], } \\
\text { or grass athletics track [39] suitable. } \\
\text { Human = two members of staff }=\text { one to } \\
\text { time and one to record results [10, 17]]. } \\
\text { Training = no advanced technical } \\
\text { training requirements }\end{array}$ \\
\hline Total & & 1 & & 1 & \\
\hline $\begin{array}{l}\text { Practical } \\
\text { implementation } \\
\text { issues }\end{array}$ & & 2 & $\begin{array}{l}\text { For a single study, } 22(37.9 \%) \text { children and } \\
25(33.3 \%) \text { adolescents experienced } \\
\text { some degree of DOMS, from which six } \\
\text { children }(10.3 \%) \text { and four adolescents } \\
(5.3 \%) \text { indicated that their DOMS was } \\
\text { severe. Three }(2.3 \%) \text { subjects reported } \\
\text { having severe pain in the upper body, } 29 \\
(21.8 \%) \text { in lower body, and } 14(10.5 \%) \\
\text { in the whole body. Most (39 participants; } \\
29.3 \%) \text { assumed that the } 20 \text {-m shuttle run } \\
\text { test could be the cause. For } 11 \text { (19\%) } \\
\text { children and } 14(18.7 \%) \text { adolescents, } \\
\text { DOMS caused difficulties in daily } \\
\text { activities, especially stair climbing and } \\
\text { walking [34] }\end{array}$ & 1 & $\begin{array}{l}\text { Participants may have difficulty in } \\
\text { developing an appropriate pace; } \\
\text { participants may either start too fast so } \\
\text { that they are not able to keep up the speed } \\
\text { all through the test, or they may start too } \\
\text { slow so that when they want to increase } \\
\text { speed, the test is already finished [4] }\end{array}$ \\
\hline Total & & 2 & & 1 & \\
\hline
\end{tabular}


Table 6 continued

\begin{tabular}{|c|c|c|c|}
\hline \multirow[t]{2}{*}{ Component } & \multirow[t]{2}{*}{ Variable } & 20-m shuttle run test & 1 mile run/walk \\
\hline & & Score Comment & Score Comment \\
\hline $\begin{array}{l}\text { Overall weighted } \\
\text { score }\end{array}$ & & 34 & 25 \\
\hline
\end{tabular}

$P E$ physical education, $C D$ compact disc, DOMS delayed onset muscle soreness

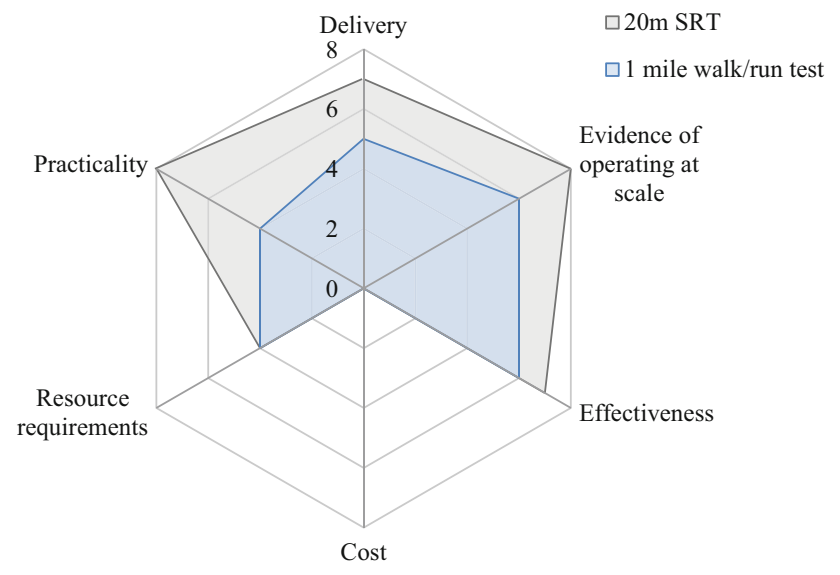

Fig. 2 Scalability scores for $20 \mathrm{~m}$ SRT compared with 1 mile walk/ run test. $S R T$ shuttle run test

criterion of scalability is critical to policymakers and practitioners. As little is known about the scalability of fitness tests for children, in the present paper we presented data that will facilitate future decision making as to test provision, whilst also proposing a framework that could be applied to examine scalability in the context of either new data relating to existing tests or of data pertaining to new tests. Using this method we demonstrated that, based on available data, the $20-\mathrm{m}$ shuttle run test is likely more scalable than the 1-mile walk/run test, with these tests scoring 34 and 25 of 48, respectively. However, a word of caution is required here given the stark contrast between the number of studies initially identified and the number of studies that met the inclusion criteria.

Whilst it is entirely understandable that scientific reports of fitness tests do not require the reporting of non-scientific data points such as costs, it is probably reasonable to suggest that with the increasing emphasis on real-world application and impact, it is incumbent on journal editors and reviewers, as well as policymakers and those funding research, to push for greater reporting of all such data where appropriate (this would perhaps be analogous to the way that the broader acceptance of meta-analysis as the gold standard of research synthesis has encouraged editors and funders to require the reporting effect sizes and/or all necessary data points to calculate these). We hope that this paper, by identifying the core components of scalability in the context of children's fitness testing might encourage that process.

It is important to acknowledge limitations of the methodology reported. Firstly, as is the case with many if not most attempts at research synthesis, there was a stark contrast between the number of studies initially identified and the number of studies that met the inclusion criteria. This was likely compounded by our two-stage analysis. Without the reporting of all relevant data, however, it is problematic to evaluate scalability, and this was especially the case with regard to cost-effectiveness/affordability of test delivery, economies of scale, and marginal costs, for which no information could be found for either of the two fitness tests addressed in this study.

Second, in examining the literature we found only limited information on the definition of scalability and its core constituents. Therefore there are potentially one or more components of scalability that are not incorporated in our framework. For example, ethical consideration could be an important a priori factor in light of emerging web-based technologies.

Third, and related to the second, given this was a pioneering approach we had no a priori reason to justify weighting certain components within the framework more heavily than others. However it may be that in practice/ application of the model, fundamental constraints to testing may evolve and the model may need to be developed accordingly. Such constraints may differ depending on who is applying the framework, for example whilst researchers may be more focused on ethics and controls, practitioners and policymakers may be more focused on costs.

\section{Conclusions}

Recent systematic reviews by Castro-Piñero et al. [4] and Artero et al. [5] indicated strong support for the validity and reliability of the 20-m shuttle run test in the context of children's fitness testing. Our analysis above should further encourage practitioners and policymakers to adopt this test either as an adjunct to, or replacement for, existing mandated tests such as the UK NCMP.

We also believe that the scalability framework developed in this paper has value beyond that of the context 
above. It has potential value in establishing the scalability of many types of fitness tests and/or measures, as well as in informing policy-makers in the up scaling of interventions from small projects or controlled trials to wider state, national or international programs.

Acknowledgments The authors would like to thank Premier Sport UK for supporting the production of this manuscript.

\section{Compliance with Ethical Standards}

Funding The project was part funded by Premier Sport, UK.

Conflict of interest Sarah Domone, Chris Beedie, Gavin Sandercock, Matthew Wade and Steven Mann declare that they have no conflicts of interest relevant to the content of this review. However, Gavin Sandercock is a shareholder in FitmediaFitness, which delivers fitness assessments in schools in the UK.

Open Access This article is distributed under the terms of the Creative Commons Attribution 4.0 International License (http:// creativecommons.org/licenses/by/4.0/), which permits unrestricted use, distribution, and reproduction in any medium, provided you give appropriate credit to the original author(s) and the source, provide a link to the Creative Commons license, and indicate if changes were made.

\section{References}

1. Case A, Fertig A, Paxson C. The lasting impact of childhood health and circumstance. J Health Econ. 2005;24:365-89.

2. Department of Health. On the state of the public health. The 2009 Annual Report of the Chief Medical Officer. London; 2010.

3. Guo SS, Chumlea WC. Tracking of body mass index in children in relation to overweight in adulthood. Am $\mathrm{J}$ Clin Nutr. 1999;70:145S-8S.

4. Castro-Piñero J, Artero EG, España-Romero V, et al. Criterionrelated validity of field-based fitness tests in youth: a systematic review. Br J Sports Med. 2010;44:934-43.

5. Artero EG, España-Romero V, Castro-Piñero J, et al. Reliability of field-based fitness tests in youth. Int $\mathrm{J}$ Sports Med. 2011;32:159-69.

6. Milat AJ, King L, Newson R, et al. Increasing the scale and adoption of population health interventions: experiences and perspectives of policy makers, practitioners, and researchers. Health Res Policy Syst. 2014;12:18.

7. DeVellis R. Scale development: theory and applications. Thousand Oaks: Sage Publications; 2003.

8. Milat AJ, King L, Bauman AE, et al. The concept of scalability: increasing the scale and potential adoption of health promotion interventions into policy and practice. Health Promot Int. 2013;28:285-98.

9. Baquet G, Berthoin S, Gerbeaux M, et al. High-intensity aerobic training during a 10 week one-hour physical education cycle: effects on physical fitness of adolescents aged 11 to 16 . Int $\mathbf{J}$ Sports Med. 2001;22:295-300.

10. Beets MW, Pitetti KH. Criterion-referenced reliability and equivalency between the PACER and 1-mile run / walk for high school students. J Phys Act Health. 2006;3:21-33.

11. Boddy LM, Fairclough SJ, Atkinson G, et al. Changes in cardiorespiratory fitness in 9- to 10.9-year-old children: Sportslinx 1998-2010. Med Sci Sports Exerc. 2012;44:481-6.
12. Boreham C, Twisk JOS, Murray L, et al. Fitness, fatness, and coronary heart disease risk in adolescents: the Northern Ireland Young Hearts Project. Med Sci Sport Exerc. 2001;33:270-4.

13. Burns R, Hannon JC, Brusseau TA, et al. Indices of abdominal adiposity and cardiorespiratory fitness test performance in middle-school students. J Obes. 2013.

14. Castro-Pineiro J, Ortega FB, Keating XD, et al. Percentile values for aerobic performance running/walking field tests in children aged 6 to 17 years: influence of weight status. Nutr Hosp. 2011;26(3):572-8.

15. Jenner DA, Vandongen R, Beilin LJ. Relationships between blood pressure and measures of dietary energy intake, physical fitness, and physical activity in Australian children aged 11-12 years. J Epidemiol Community Health. 1992;46:108-13.

16. Kim J, Must A, Fitzmaurice GM, et al. Relationship of physical fitness to prevalence and incidence of overweight among schoolchildren. Obes Res. 2005;13:1246-54.

17. Mahar MT, Rowe DA, Parker CR, et al. Criterion-referenced and norm-referenced agreement between the mile run. Meas Phys Educ Exerc Sci. 1997;4:245-58.

18. Mahoney C. 20-MST and PWC170 validity in non-Caucasian children in the UK. Br J Sports Med. 1992;26:45-7.

19. Matsuzaka A, Takahashi Y, Yamazoe M, et al. Validity of the multistage 20-m shuttle-run test for Japanese children, adolescents, and adults. Pediatr Exerc Sci. 2004;16:113-25.

20. Ortega FB, Artero EG, Ruiz JR, et al. Reliability of health-related physical fitness tests in European adolescents: the HELENA Study. Int J Obes. 2008;32(Suppl 5):S49-57.

21. Ortega FB, Artero EG, Ruiz JR, et al. Physical fitness levels among European adolescents: the HELENA study. Br J Sports Med. 2011;45:20-9.

22. Quinart S, Mougin F, Simon-Rigaud M-L, et al. Evaluation of cardiorespiratory fitness using three field tests in obese adolescents: validity, sensitivity and prediction of peak VO2. J Sci Med Sport. 2014;17:521-5.

23. Roberts SJ, Boddy LM, Fairclough SJ, et al. The influence of relative age effects on the cardiorespiratory fitness levels of children age 9 to 10 and 11 to 12 years of age. Pediatr Exerc Sci. 2012;24:72-83.

24. Sandercock G, Voss C, Gladwell V. Twenty-metre shuttle run test performance of English children aged 11-15 years in 2007: comparisons with international standards. J Sports Sci. 2008;26:953-7.

25. Sandercock G, Ogunleye A, Voss C. Comparison of cardiorespiratory fitness and body mass index between rural and urban youth: Findings from the East of England Healthy Hearts Study. Pediatr Int. 2011;53:718-24.

26. Sandercock G, Voss C, Cohen D, et al. Centile curves and normative values for the twenty metre shuttle-run test in English schoolchildren. J Sports Sci. 2012;30:679-87.

27. Stratton G, Canoy D, Boddy LM, et al. Cardiorespiratory fitness and body mass index of 9-11-year-old English children: a serial cross-sectional study from 1998 to 2004. Int J Obes (Lond). 2007:31:1172-8.

28. Voss C, Sandercock G. Does the twenty meter shuttle-run test elicit maximal effort in 11- to 16-year-olds? Pediatr Exerc Sci. 2009;21:55-62.

29. Voss C, Sandercock G. Aerobic fitness and mode of travel to school in English schoolchildren. Med Sci Sports Exerc. 2010;42:281-7.

30. Voss C, Sandercock G. Associations between perceived parental physical activity and aerobic fitness in schoolchildren. J Phys Act Health. 2013;10:397-405.

31. Buono MJ, Roby JJ, Micale FG, et al. Validity and reliability of predicting maximum oxygen uptake via field tests in children and adolescents. Pediatr Exerc Sci. 1991;3:250-5. 
32. Cureton K, Sloniger M, O'Bannon J, et al. A generalized equation for prediction of $\mathrm{VO} 2$ peak from 1-mile run/walk performance. Med Sci Sports Exerc. 1994;27:445-51.

33. Hunt BR, George JD, Vehrs PR, et al. Validity of a submaximal 1-mile track jog test in predicting $\mathrm{VO} 2$ max in fit teenagers. Pediatr Exerc Sci. 2000;12:80-90.

34. España-Romero V, Artero EG, Jimenez-Pavón D, et al. Assessing health-related fitness tests in the school setting: reliability, feasibility and safety; the ALPHA study. Int $\mathrm{J}$ Sports Med. 2010;31:490-7.

35. Leger LA, Lambert J. A maximal multistage 20-m shuttle run test to predict VO2 max. Eur J Appl Physiol Occup Physiol. 1982;49:1-12.
36. Léger LA, Mercier D, Gadoury C, et al. The multistage 20 metre shuttle run test for aerobic fitness. J Sports Sci. 1988;6:93-101.

37. Welk GJ, Meredith M. Fitnessgram/activitygram reference guide. Dallas: The Cooper Institute; 2008.

38. Zhu X. Situational interest and physical activity in fitness testing: a need for pedagogical engineering. Int J Sport Exerc Psychol. 2013;12:76-89.

39. Cureton KJ, Sloniger MA, O'Bannon JP, et al. A generalized equation for prediction of VO2peak from 1-mile run/walk performance. Med Sci Sports Exerc. 1995;27:445-51.

40. Robertson SJ, Burnett AF, Cochrane J. Tests examining skill outcomes in sport: a systematic review of measurement properties and feasibility. Sports Med. 2014;44:501-18. 